\title{
A Phase II Trial of Fixed-Dose Rate Gemcitabine plus Capecitabine in Metastatic/Advanced Biliary Tract Cancer Patients
}

\author{
Daniele Santini $^{a}$ Vladimir Virzi $^{\mathrm{a}}$ Enrico Vasile ${ }^{\mathrm{b}}$ Bruno Vincenzi ${ }^{\mathrm{a}}$ \\ Vincenzo Catalanoc Francesco Grazianoc ${ }^{c}$ Gianluca Masi ${ }^{b}$ Giuseppe Bronte ${ }^{d}$ \\ Antonio Russo $^{d} \quad$ Alfredo Falcone $^{b}$ Giuseppe Tonini ${ }^{a}$ \\ ${ }^{a}$ Medical Oncology, University Campus Bio-Medico, Rome, ${ }^{b}$ Division of Medical Oncology, Department of \\ Oncology, Livorno, 'Department of Medical Oncology, Azienda Ospedaliera 'Ospedale San Salvatore', Pesaro, and \\ ${ }^{\mathrm{d}}$ Section of Medical Oncology, Department of Surgical and Oncological Sciences, University of Palermo, \\ Palermo, Italy
}

\section{Key Words}

Capecitabine $\cdot$ Fixed-dose rate $\cdot$ Gemcitabine $\cdot$ Biliary tract cancer

\begin{abstract}
Background: This phase II trial was conducted to determine the activity and safety of the combination of fixed-dose rate (FDR) gemcitabine and capecitabine in metastatic biliary tract cancer (BTC) patients. Methods: Patients with unresectable BTC who had pathologically confirmed adenocarcinoma, no prior chemotherapy, Eastern Cooperative Oncology Group (ECOG) performance status $\leq 1$ and measurable disease were enrolled. Treatment consisted of FDR gemcitabine at $800 \mathrm{mg} / \mathrm{m}^{2}$ on days 1 and 8 every 21 days with capecitabine administered orally b.i.d. in equal doses $\left(650 \mathrm{mg} / \mathrm{m}^{2}\right.$ b.i.d.) for 14 days (28 doses). Results: Between May 2005 and February 2009, 30 patients were enrolled. The median age was 67 years (45-76) and there were 14 males. Thirty patients were evaluable for response and toxicity. A total of 221 cycles were administered (median 7, range 2-16). One patient achieved complete response and 7 patients achieved partial response, giving an overall response rate of $26.7 \%$ in the intention-to-treat population. Twelve patients (40.0\%) had sta-
\end{abstract}

ble disease. The median progression-free survival was 6.33 months. The median overall survival was 10.8 months. Grade 3/4 neutropenia and thrombocytopenia were noted in 13 and $7 \%$ of the patients, respectively. Grade $2 / 3$ nonhematologic toxicities were asthenia (54\% of patients), diarrhea (17\%), stomatitis (23\%) and hand-foot syndrome (7\%). There was no treatment-related death. The drugs taken were skipped at least once in $45 \%$ of the patients and the dose was reduced in $26 \%$ of them. Conclusions: The combination of FDR gemcitabine and capecitabine in this 3-week cycle is safe and seems to have a good activity in advanced biliary cancer.

Copyright $\odot 2012$ S. Karger AG, Basel

\section{Introduction}

Biliary tract cancers (BTC) are relatively rare tumors with a dismal prognosis [1]. This kind of tumor is more likely to occur in patients aged between 50 and 70 years. As far as the role of nonsurgical oncologic treatment is concerned, the only standard regimen for advanced disease has recently been established. In fact, the ABC-02 study, a practice-changing phase III study, recognized the

\section{KARGER}

Fax +41613061234 E-Mail karger@karger.ch www.karger.com

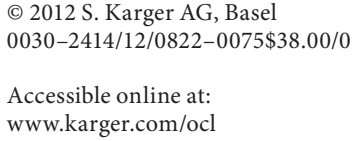

Tel. +39091655 2500, E-Mail lab-oncobiologia@usa.net 
gemcitabine/cisplatin regimen as the standard of care, with a stable disease rate of $81 \%$, progression-free survival (PFS) of 8 months and median overall survival (OS) of 11.7 months. Due to clinical conditions, patients who receive palliative chemotherapy are usually treated with single-agent gemcitabine or with combination regimens including mitomycin or fluoropyrimidines $[2,3]$. Response rates with these treatments range from 10 to $35 \%$, and median OS time varies between 5 and 12 months [4]. Nevertheless, the small number of published trials and the considerable variability in the patients' clinical characteristics make the data difficult to interpret. Nowadays, there is no standard chemotherapy regimen in BTC. Several reports have demonstrated that gemcitabine is active in BTC [5-7]. Capecitabine (Xeloda ${ }^{\mathrm{TM}}$; Hoffmann-La Roche, Basel, Switzerland) is an oral fluoropyrimidine carbamate that selectively generates 5 -FU in tumor tissues. Gemcitabine also appears to modulate the activity of 5-fluorouracil (5-FU) in renal and gastrointestinal malignancies $[8,9]$. Capecitabine offers the possibility of continuous tumor exposure to 5-FU by preferential activation at the tumor, while potentially minimizing the exposure of healthy body tissues to systemic 5 -FU [10, 11]. Moreover, 5-FU has demonstrated activity in BTC [12]. As shown in our phase I study, to enhance the cytotoxic activity of gemcitabine, an alternative infusion regimen has been explored [13]. As the active metabolite of gemcitabine, 2',2'-difluorodeoxycytidine triphosphate (dFdCTP), has a long intracellular half-life, a fixed-dose rate (FDR) infusion of $10 \mathrm{mg} / \mathrm{m}^{2} / \mathrm{min}$ has been shown to lead to maximal intracellular accumulation. In particular, it has been demonstrated that increasing the infusion time while holding the dose rate constant at $10 \mathrm{mg} /$ $\mathrm{m}^{2} / \mathrm{min}$ could result in increased intracellular levels of dFdCTP, thus enhancing the activity of gemcitabine [14, 15]. On the basis of phase I results, the dose of FDR gemcitabine $800 \mathrm{mg} / \mathrm{m}^{2}$ in $80 \mathrm{~min}$ on days 1 and 8 plus capecitabine $650 \mathrm{mg} / \mathrm{m}^{2}$ b.i.d., for 14 consecutive days followed by 1 week of rest, is a recommended schedule that we used in this study. This is a phase II study evaluating toxicity, response, and survival associated with using a combination of FDR gemcitabine and capecitabine to treat patients with unresectable or metastatic BTCs.

\section{Patients and Methods}

\section{Eligibility}

Patients with histologically confirmed unresectable or metastatic BTC adenocarcinomas, including those who were at least 18 years old and who had an Eastern Cooperative Oncology Group
(ECOG) performance status $\leq 1$, were considered suitable for the study. The following hematologic and chemistry parameters were recommended: absolute neutrophil count $1,500 / \mathrm{mm}^{3}$, platelet count $100,000 / \mathrm{mm}^{3}$, hemoglobin $10.0 \mathrm{~g} / 100 \mathrm{ml}$, preserved renal function (serum creatinine $1.6 \mathrm{mg} / \mathrm{dl}$, normal creatinine clearance), and hepatic function (total bilirubin $1.5 \mathrm{mg} / \mathrm{dl}$, aspartate aminotransferase and alanine aminotransferase $2.5 \times$ normal without hepatic metastasis and $4 \times$ normal with hepatic metastasis, serum alkaline phosphatase $<2.5 \times$ the upper limit of normal or $<5 \times$ the upper limit of normal if liver metastases were present or $<10 \times$ the upper limit of normal if bone metastases were present). A basal cardiac function evaluation was required.

Major exclusion criteria included radiotherapy or chemoradiotherapy treatment within the previous 4 weeks ( 6 weeks if the previous therapy included nitrosourea or mitomycin C). Patients previously treated with chemotherapy for metastatic disease were excluded. Concomitant use of amiodarone, ketoconazole, itraconazole, diltiazem, verapamil, barbiturates, and warfarin was not permitted. Pregnant or lactating patients were excluded from the study. Patients with significant stomach, small intestine, liver, or kidney disease likely to affect drug absorption or metabolism were excluded from the study. Other contraindications included a history of coagulopathy or brain or other central nervous system metastases. Patients with any history of a previous malignancy diagnosed within 5 years were also excluded, with the exception of basal cell carcinoma or skin and cervical carcinoma in situ. Additionally, patients were excluded if adequate follow-up was not possible (geographic difficulties, no compliance with necessary clinical-instrumental investigations, etc.).

All patients were required to provide written informed consent before initiation of treatment after a complete and clear explanation. Approval of the local ethics committee was obtained. The trial was conducted in accordance with the declaration of Helsinki.

\section{Treatment and Dose Modifications}

Capecitabine $\left(650 \mathrm{mg} / \mathrm{m}^{2}\right.$ b.i.d.) was administered orally twice a day for 14 consecutive days followed by 1 week of rest. It was supplied as film-coated Xeloda tablets in two dosage strengths, 150 -mg and 500-mg tablets, administered in nonfasting conditions and swallowed with water. Gemcitabine (Gemzar ${ }^{\mathrm{TM}}$ ) was given at an FDR dose of $800 \mathrm{mg} / \mathrm{m}^{2}$ in $80 \mathrm{~min}$ on days 1 and 8 of each cycle. The drug was prepared for administration according to the directions in the package. Cycles were repeated every 21 days. All patients had their medical history taken and had a full physical examination with radiologic and laboratory evaluations. History, physical examination, and laboratory tests were repeated on day 1 of each cycle of therapy. Prophylactic administration of recombinant human granulocyte colony-stimulating factor was not allowed. In cases where the patient had grade 3 or 4 afebrile neutropenia, subsequent cycles were repeated with recombinant human granulocyte colony-stimulating factor, and capecitabine and gemcitabine doses were reduced by $25 \%$. In cases of grade 3 or 4 thrombocytopenia lasting more than 7 days, the doses of both drugs were also reduced by $25 \%$. The doses of capecitabine were reduced by $25 \%$ in cases of grade 3 or 4 diarrhea or hand-foot syndrome.

\section{Efficacy and Safety Evaluation}

Tumor assessment according to RECIST criteria was performed at 9 -week intervals by the investigators [16]. Tumor lesions 
were assessed by computed tomography scanning, X-rays or magnetic resonance imaging. Responding patients or those with stable disease (SD; $>3$ months) could continue treatment until progression of disease (PD), unacceptable toxicity or their decision to stop. PFS was calculated as the time from the time of inclusion in the study to the first record of PD or the date of death if the patient died before PD was demonstrated. Survival was monitored every 3 months after the patient completed treatment. Safety was monitored during the study and for 28 days after the last cycle treatment. Adverse events were graded according to the National Cancer Institute of Canada-Common Toxicity Criteria (NCI-CTC) [17]. PFS and OS were analyzed by the Kaplan-Meier method. Those patients who did not receive at least one dose of study medication or for whom no follow-up safety information was available were excluded.

\section{Statistical Analysis}

The Simon optimal two-stage design was chosen for sample size calculation. The expected number of patients for accrual in this study was calculated to reject a $10 \%$ response rate in favor of a target response rate of $30 \%$. This condition allows a significance level of 0.05 with a statistical power of $90 \%$. The preliminary activity of this new combination will be assessed enrolling 9 patients. If there was $<1$ response, accrual needed to be terminated. Otherwise, 21 additional patients need to be entered in the second stage to achieve a target sample size of 30 evaluable patients for tumor response. If more than 4 responses were observed in these 30 patients, further assessment could be suggested. RECIST criteria were considered for the evaluation of response. Kaplan-Meier survival curves were generated based on the PFS and OS data and analyzed by the log-rank statistic.

\section{Results}

\section{Patient Characteristics}

Thirty patients were enrolled between May 2005 and February 2009. The median age was 67.0 years (range $45-$ 76); there were 17 (55\%) females and 14 (45\%) males. All patients completed the first two cycles of therapy and were, therefore, assessable for toxicity and for efficacy. ECOG performance status was 0 in 24 (77\%) of patients and 1 in the other 7 (23\%). Seven (23\%) patients needed biliary drainage. The distribution of primary cancer was: gallbladder in 13 (42\%) patients, ampulla of Vater in 2 (6\%) patients, intrahepatic cholangiocarcinoma in 9 (29\%) patients and extrahepatic bile duct in 7 (23\%) patients. A total of 221 cycles were administered; the median number of cycles for a patient was 7.0 (range 2-16). The median follow-up was 22.3 months. As shown in table 1 , the majority of patients $(97 \%)$ had stage IV disease and the most commonly affected metastatic sites were liver (81\%) and abdominal lymph nodes (35\%).
Table 1. Patient characteristics

\begin{tabular}{lc}
\hline Characteristic & Number of patients \\
\hline Evaluable patients & $30(97 \%)$ \\
Gender & $14(45 \%)$ \\
Male & $17(55 \%)$ \\
$\quad$ Female & $67(45-76)$ \\
Age, years & \\
Median (range) & $24(77 \%)$ \\
ECOG performance status & $7(23 \%)$ \\
0 & $1(3 \%)$ \\
1 & $30(97 \%)$ \\
Disease at presentation & $13(42 \%)$ \\
Locally advanced & $2(6 \%)$ \\
Metastatic disease & $9(29 \%)$ \\
Primary disease & $7(23 \%)$ \\
Gallbladder & \\
Ampulla of Vater & $1(0-5)$ \\
Intrahepatic cholangiocarcinoma & \\
Extrahepatic bile duct cancer & $25(81 \%)$ \\
Metastatic sites & $11(35 \%)$ \\
Median (range) & $2(6 \%)$ \\
Sites of metastatic disease & $1(3 \%)$ \\
Liver & $4(13 \%)$ \\
Lymph nodes &
\end{tabular}

Table 2. Treatment-related toxicity

\begin{tabular}{|c|c|c|c|c|}
\hline \multirow[t]{2}{*}{ Toxicity } & \multicolumn{4}{|c|}{ Number of patients $(n=30)$} \\
\hline & grade 1 & grade 2 & grade 3 & grade 4 \\
\hline \multicolumn{5}{|l|}{ Hematologic } \\
\hline Neutropenia & $1(3 \%)$ & $9(30 \%)$ & $3(10 \%)$ & $1(3 \%)$ \\
\hline Leukopenia & $3(10 \%)$ & $3(10 \%)$ & $2(7 \%)$ & \\
\hline Thrombocytopenia & $3(10 \%)$ & $4(13 \%)$ & $2(7 \%)$ & \\
\hline Anemia & $14(47 \%)$ & $5(16 \%)$ & & \\
\hline \multicolumn{5}{|l|}{ Nonhematologic } \\
\hline Nausea & $13(43 \%)$ & $6(20 \%)$ & & \\
\hline Diarrhea & $9(30 \%)$ & $3(10 \%)$ & $2(7 \%)$ & \\
\hline Stomatitis & $6(20 \%)$ & $6(20 \%)$ & $1(3 \%)$ & \\
\hline Elevated AST & $4(13 \%)$ & & & \\
\hline Fatigue & $8(27 \%)$ & $11(37 \%)$ & $5(17 \%)$ & \\
\hline HFS & $3(10 \%)$ & $2(7 \%)$ & & \\
\hline
\end{tabular}

Toxicity was graded according to the second version of the Common Toxicity Criteria of the National Cancer Institute. AST = Aspartate aminotransferase; HFS = hand-foot syndrome. 


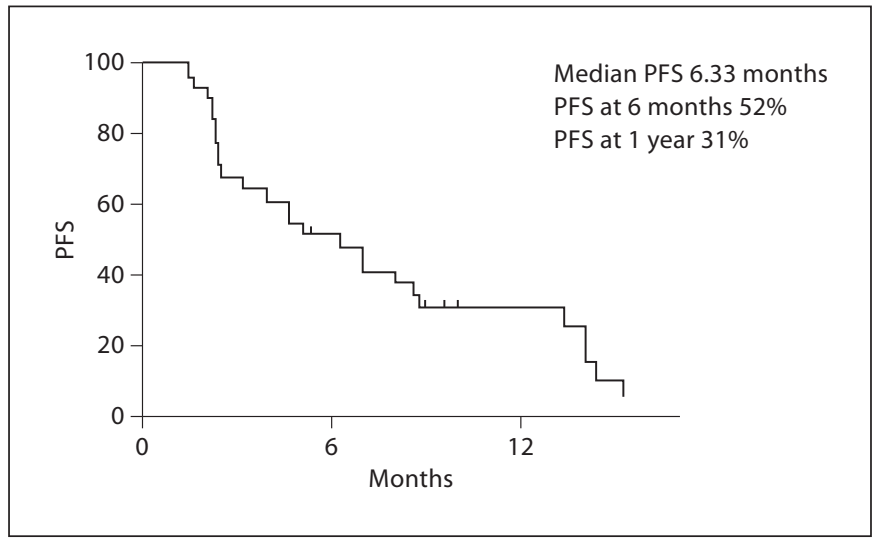

Fig. 1. PFS: median, at 6 months, and at 1 year.

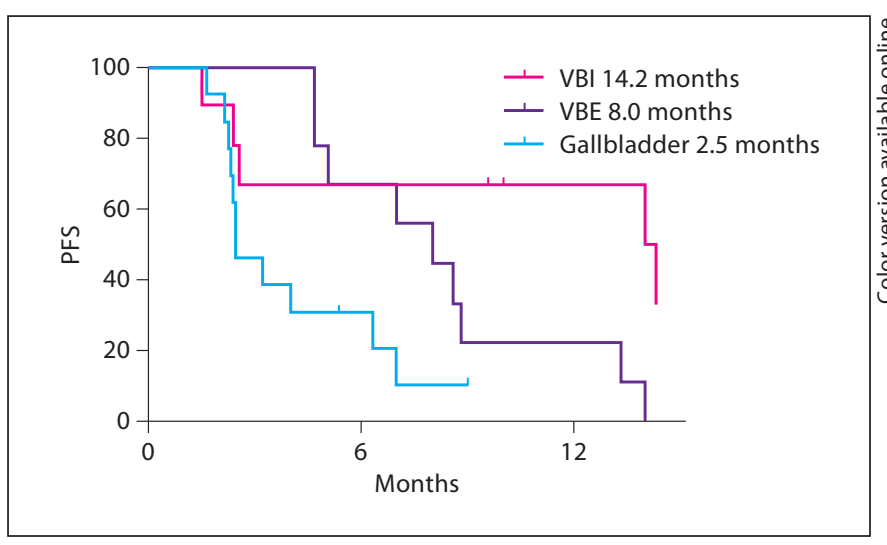

Fig. 2. PFS for primary sites: VBI, VBE and gallbladder.

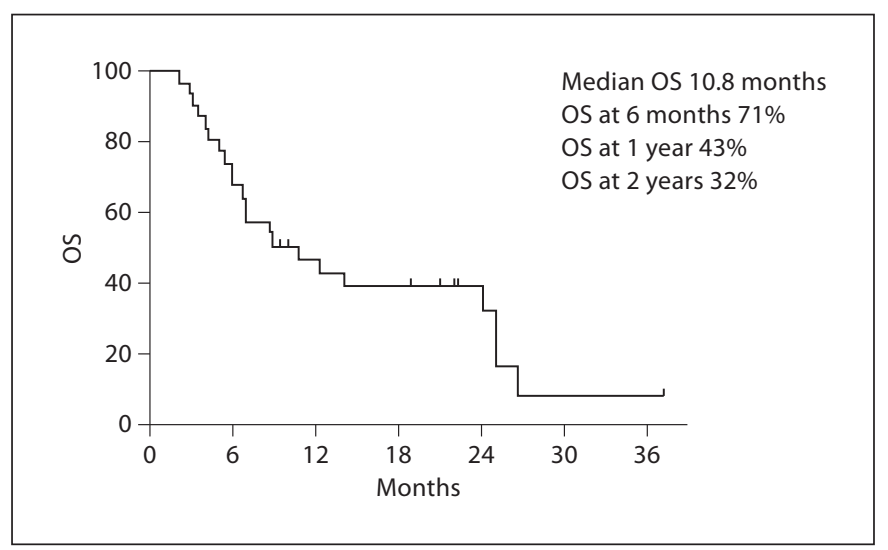

Fig. 3. OS: median, at 6 months, and at 1 and 2 years.
Table 3. Therapeutic results

\begin{tabular}{lc}
\hline Result & Number of patients \\
\hline Complete response & $1(3 \%)$ \\
Partial response & $7(23 \%)$ \\
SD & $12(40 \%)$ \\
PD & $10(33 \%)$ \\
\hline
\end{tabular}

\section{Safety}

Table 2 summarizes the observations on toxicity. Nonhematologic adverse events (G2 percentage/G3 percentage) were: nausea (20/0), hand-foot syndrome (7/0), general weakness (37/17), stomatitis (20/3), and diarrhea (10/7). One patient (3\%) experienced G4 nonfebrile neutropenia. Grade 3 neutropenia, anemia, and thrombocytopenia were present in 10, 0 and $7 \%$ of patients, respectively. Eight patients (27\%) had reduced drug doses for neutropenia (2), thrombocytopenia (1), diarrhea (2), general weakness (2), and hand-foot syndrome (1). Fourteen patients (47\%) needed to delay chemotherapy because of neutropenia (5). No deaths occurred during the study which could be attributed to toxicity.

\section{Efficacy}

The median duration of treatment for all patients was 143 days (range 34-390 days). Seven (23\%) of 30 evaluated patients (1 patient excluded for causes not associated with the tumor) obtained a partial response, 1 patient (3\%) had a complete response, and 12 patients (40\%) had SD obtaining tumor control (complete response + partial response $+\mathrm{SD})$ of $66 \%$. Ten patients (33\%) had PD. The median PFS was 6.33 months. PFS were 52 and $31 \%$ at 6 months and 1 year, respectively (fig. 1). The subgroup analysis showed a PFS of 14.2, 8 and 2.5 months in intrahepatic biliary tract (VBI), extrahepatic biliary tract (VBE) and in gallbladder, respectively (fig. 2). The median OS for the entire population was 10.8 months (fig. 3). At 6 months, 1 year and 2 years, 71,43 and $32 \%$ of patients were alive, respectively. Efficacy data are shown in table 3.

\section{Discussion}

At the moment, there is no standard chemotherapy regimen for advanced biliary cancer. Historically, chemotherapy had little impact on the natural history of this disease. There are several reasons for this: a lack of active agents, the overall morbidity of treatment and conse- 
Table 4. Recent clinical trials of biliary cancer

\begin{tabular}{|c|c|c|c|c|c|}
\hline Author, year, Ref. No. & Regimen & No. & Tumor sites & $\mathrm{RR}, \%$ & OS, months \\
\hline Gallardo, 2001 [20] & gemcitabine & 26 & gallbladder & 35 & 7.5 \\
\hline Kuhn, 2002 [21] & gemcitabine/docetaxel & 43 & gallbladder + bile duct & 9 & 11 \\
\hline Taieb, 2002 [22] & cisplatin/5-FU & 29 & gallbladder + bile duct & 34 & 9.5 \\
\hline Nehls, 2003 [23] & capecitabine/oxaliplatin & 29 & gallbladder + bile duct & 23 & 9.5 \\
\hline Reyes-Vidal, 2003 [24] & gemcitabine/cisplatin & 44 & gallbladder & 45 & 7 \\
\hline Patt, 2004 [25] & capecitabine & 26 & gallbladder + bile duct & 17 & 7 \\
\hline Eng, $2004[26]$ & fixed-dose gemcitabine & 15 & bile duct & 0 & 5 \\
\hline Kornek, 2004 [27] & $\begin{array}{l}\text { mitomycin/gemcitabine vs. } \\
\text { mitomycin/capecitabine }\end{array}$ & 51 & bile duct & $\begin{array}{l}20 \\
31 \\
\end{array}$ & $\begin{array}{l}6.7 \\
9 \text { (P no sign }) \\
\end{array}$ \\
\hline Knox, 2005 [28] & gemcitabine/capecitabine & 45 & gallbladder + bile duct & 30 & 14 \\
\hline Rao, 2005 [29] & $\begin{array}{l}\text { 5-FU/leucovorin vs. } \\
\text { ECF }\end{array}$ & 54 & bile duct & $\begin{array}{l}19 \\
15\end{array}$ & $\begin{array}{l}12 \\
9 \text { (P no sign })\end{array}$ \\
\hline Ducreux, 2005 [30] & $\begin{array}{l}\text { 5-FU vs. } \\
\text { 5-FU/cisplatin }\end{array}$ & 58 & bile duct & $\begin{array}{r}7 \\
19 \\
\end{array}$ & $\begin{array}{l}5 \\
8 \text { (P no sign }) \\
\end{array}$ \\
\hline Julka, 2006 [31] & gemcitabine/oxaliplatin & 20 & gallbladder & 36.7 & ND \\
\hline Lee, 2006 [32] & gemcitabine/oxaliplatin & 24 & bile duct & 21 & 9.3 \\
\hline Philip, 2006 [33] & erlotinib & 42 & bile duct & 7 & ND \\
\hline Manzione, 2007 [34] & gemcitabine/oxaliplatin & 34 & gallbladder + bile duct & 41 & 10 \\
\hline Hong, 2007 [35] & capecitabine/cisplatin & 32 & gallbladder + bile duct & 40.6 & 12.4 \\
\hline Riechelmann, 2007 [36] & gemcitabine/capecitabine & 75 & gallbladder + bile duct & 29 & 12.7 \\
\hline Andre, 2008 [37] & gemcitabine/oxaliplatin & 45 & gallbladder + bile duct & 33 & 8.3 \\
\hline $\operatorname{Im}, 2008$ [38] & S1/cisplatin & 51 & gallbladder + bile duct & 30 & 8.7 \\
\hline Furuse, 2008 [39] & S1 & 40 & gallbladder + bile duct & 35 & 9.4 \\
\hline Meyerhardt, 2008 [40] & gemcitabine/cisplatin & 30 & gallbladder + bile duct & 21 & 9.7 \\
\hline Valle, 2009 [41] & $\begin{array}{l}\text { gemcitabine vs. } \\
\text { gemcitabine/cisplatin }\end{array}$ & 86 & gallbladder + bile duct & $\begin{array}{l}15 \\
24 \\
\end{array}$ & ND \\
\hline Wagner, 2009 [42] & gemcitabine/oxaliplatin/5-FU & $\begin{array}{l}37 \\
35 \\
\end{array}$ & $\begin{array}{l}\text { bile duct } \\
\text { gallbladder }\end{array}$ & $\begin{array}{l}19 \\
23 \\
\end{array}$ & $\begin{array}{c}10 \\
9.9 \\
\end{array}$ \\
\hline Sasaki, 2009 [43] & S1/gemcitabine & 35 & gallbladder + bile duct & 34.3 & 11.6 \\
\hline Kim, 2009 [44] & gemcitabine/oxaliplatin & 40 & gallbladder + bile duct & 15 & 8.5 \\
\hline Ramanathan, 2009 [45] & lapatinib & 17 & bile duct & 0 & 5.2 \\
\hline Yamashita, 2010 [46] & gemcitabine/cisplatin/5-FU & 21 & bile duct & 33.3 & 18.8 \\
\hline Sharma, 2010 [47] & gemcitabine/oxaliplatin & 50 & gallbladder & 21.2 & 7.5 \\
\hline Jang, $2010[48]$ & gemcitabine/oxaliplatin & 53 & gallbladder + bile duct & 18.9 & 8.3 \\
\hline
\end{tabular}

No. = Number of enrolled patients; RR = response rate; 5-FU = 5-fluorouracil; ECF = epirubicin, cisplatin, 5-fluorouracil; P no sign = not statistically significant; $\mathrm{ND}=$ not done.

quently reduced dose intensity, and the grouping together of different cancer types with different biologies. Older chemotherapy combinations with 5-fluorouracil have demonstrated response rates of less than $15 \%$. To our knowledge, only one published randomized study has shown an improvement in quality of life for biliary cancer patients treated with 5-fluorouracil-based chemotherapy versus best supportive care, although no difference in OS was observed [18]. In table 4, the principal phase II studies are summarized, where regimens containing new agents such as gemcitabine, capecitabine, and oxaliplatin have demonstrated objective responses in $20-45 \%$ of patients and a median survival of 8-14 months. The recent approval of numerous targeted agents in a variety of solid tumors and hematologic malignancies has clearly demonstrated the clinical efficacy of such agents. How- 
ever, the overall modest activity of these agents in 'orphan' tumors such as BTC emphasizes the need for novel and more effective medical treatment options such as combinations of targeted agents with cytotoxic drugs or with other novel anticancer drugs. In our study, the combination of FDR gemcitabine and capecitabine demonstrated an interesting activity and a favorable safety in patients with advanced and/or metastatic BTC. Despite the usual limitation of cross-study comparisons, these findings compare favorably with results previously reported for 5-FU/gemcitabine combinations in patients with advanced BTC. In addition to antitumor activity, safety is a critically important target for the choice of new treatment combinations. Our combination regimen has the advantage of convenience and practicability over continuous intravenous 5-FU plus either gemcitabine or cisplatin, and has a clear potential to reduce healthcare resource expenditure. This is because capecitabine is administered orally and avoids the complications related to the use of an implanted catheter required for the continuous intravenous administration of 5-FU. In our experience, the toxicity profile is acceptable especially when compared with the toxicities reported in comparable studies. Grade 3 neutropenia and asthenia were reported in 10 and $16 \%$, respectively, and these data are superimposed with the data reported in the literature. Biliary tumors can occur anywhere in the hepatobiliary system and are often classified according to location. In the present study, cholangiocarcinoma (VBI + VBE) appeared to respond better than gallbladder carcinoma (PFS: 8.7 vs. 2.5 months, $\mathrm{p}=0.005)$, obtaining a major OS ( 25 vs. 6 months, $\mathrm{p}=0.001$ ), even if the interpretation of data is difficult because of the relatively small number of patients and the different biological and prognostic behavior of the single isotypes.

\section{Conclusions}

Further research in this area should be directed at finding the best cytotoxic agent for a combination with capecitabine or gemcitabine or altering the dose intensity or route of administration in advanced BTC. Conventional chemotherapeutic drugs have achieved only modest results in patients with BTC. Therefore, innovative therapeutic approaches are needed to obtain significant results in this type of patients. The first standard of care has been proposed at ASCO 2009 [19]. In fact, the combination of cisplatin and gemcitabine has been shown to be more effective than gemcitabine alone in a multicenter randomized phase III trial [2], and new phase III trials evaluating a different combination of chemotherapy are needed. Due to the small number of patients and the inclusion of all biliary types (ampullary, gallbladder, bile duct) in this study, these results cannot be translated in clinical practice. A larger randomized phase III trial of our combination regimen compared with gemcitabine plus cisplatin needs to be conducted to validate the efficacy of FDR gemcitabine plus capecitabine in metastatic/advanced BTC patients. Several trials are ongoing with the aim to explore the activity of the combination of chemotherapeutics with different targeted drugs inhibiting different pathways. The results of the ongoing trials are keenly awaited to definitely identify the most effective strategy in BTC.

\section{References}

1 de Groen PC, Gores GJ, LaRusso NF, Gunderson LL, Nagorney DM: Biliary tract cancers. N Engl J Med 1999;341:1368-1378.

-2 Gebbia V, Giuliani F, Maiello E, Colucci G, Verderame F, Borsellino N, Mauceri G, Caruso M, Tirrito ML, Valdesi M: Treatment of inoperable and/or metastatic biliary tree carcinomas with single-agent gemcitabine or in combination with levofolinic acid and infusional fluorouracil: results of a multicenter phase II study. J Clin Oncol 2001;19:40894091.

-3 Penz M, Kornek GV, Raderer M, Ulrich-Pur $\mathrm{H}$, Fiebiger W, Lenauer A, Depisch D, Krauss G, Schneeweiss B, Scheithauer W: Phase II trial of two-weekly gemcitabine in patients with advanced biliary tract cancer. Ann Oncol 2001;12:183-186.
Eckel F, Schmid RM: Chemotherapy in advanced biliary tract carcinoma: a pooled analysis of clinical trials. Br J Cancer 2007; 96:896-902.

-5 Burris HA 3rd, Moore MJ, Andersen J, Green MR, Rothenberg ML, Modiano MR, Cripps MC, Portenoy RK, Storniolo AM, Tarassoff P, Nelson R, Dorr FA, Stephens CD, Von Hoff DD: Improvements in survival and clinical benefit with gemcitabine as first-line therapy for patients with advanced pancreas cancer: a randomized trial. J Clin Oncol 1997;15: 2403-2413.
6 Kindler HL: Front-line therapy of advanced pancreatic cancer. Semin Oncol 2005; 32:S33-S36.

7 Rudi J: Chemotherapy with gemcitabine in patients with gall-bladder carcinoma. Ann Oncol 2002;13:807.

-8 Heinemann V, Xu YZ, Chubb S, Sen A, Hertel LW, Grindey GB, Plunkett W: Inhibition of ribonucleotide reduction in CCRF-CEM cells by $2^{\prime}, 2^{\prime}$-difluorodeoxycytidine. Mol Pharmacol 1990;38:567-572.

9 Ren Q, Kao V, Grem JL: Cytotoxicity and DNA fragmentation associated with sequential gemcitabine and 5-fluoro- 2 '-deoxyuridine in HT-29 colon cancer cells. Clin Cancer Res 1998;4:2811-2818. 
10 Miwa M, Ura M, Nishida M, Sawada N, Ishikawa T, Mori K, Shimma N, Umeda I, Ishitsuka $\mathrm{H}$ : Design of a novel oral fluoropyrimidine carbamate, capecitabine, which generates 5-fluorouracil selectively in tumours by enzymes concentrated in human liver and cancer tissue. Eur J Cancer 1998;34:12741281.

-11 Schuller J, Cassidy J, Dumont E, Roos B, Durston S, Banken L, Utoh M, Mori K, Weidekamm E, Reigner B: Preferential activation of capecitabine in tumor following oral administration to colorectal cancer patients. Cancer Chemother Pharmacol 2000;45:291297.

12 Hezel AF, Zhu AX: Systemic therapy for biliary tract cancers. Oncologist 2008;13:415423.

13 Santini D, Virzi V, Vincenzi B, Rocci L, Leoni V, Tonini G: A phase I trial of fixed dose rate gemcitabine plus capecitabine in metastatic cancer patients. Ann Oncol 2007;18: 576-580.

14 Abbruzzese JL, Grunewald R, Weeks EA, Gravel D, Adams T, Nowak B, Mineishi S, Tarassoff P, Satterlee W, Raber MN, et al: A phase I clinical, plasma, and cellular pharmacology study of gemcitabine. J Clin Oncol 1991;9:491-498.

-15 Grunewald R, Kantarjian H, Keating MJ, Abbruzzese J, Tarassoff P, Plunkett W: Pharmacologically directed design of the dose rate and schedule of $2^{\prime}, 2^{\prime}$-difluorodeoxycytidine (Gemcitabine) administration in leukemia. Cancer Res 1990;50:6823-6826.

16 Therasse P: Measuring the clinical response. What does it mean? Eur J Cancer 2002;38: 1817-1823.

17 National Cancer Institute CTC v2.0. www. eortc.be/Services/Doc/ctc/CTCvs2.doc.

- 18 Glimelius B, Hoffman K, Sjoden PO, Jacobsson G, Sellstrom H, Enander LK, Linne T, Svensson C: Chemotherapy improves survival and quality of life in advanced pancreatic and biliary cancer. Ann Oncol 1996;7: 593-600.

19 Valle J, Wasan H, Palmer DH, Cunningham D, Anthoney A, Maraveyas A, Madhusudan S, Iveson T, Hughes S, Pereira SP, Roughton $\mathrm{M}$, Bridgewater J: Cisplatin plus gemcitabine versus gemcitabine for biliary tract cancer. $\mathrm{N}$ Engl J Med 2010;362:1273-1281.

-20 Gallardo JO, Rubio B, Fodor M, Orlandi L, Yanez M, Gamargo C, Ahumada M: A phase II study of gemcitabine in gallbladder carcinoma. Ann Oncol 2001;12:1403-1406.

-21 Kuhn R, Hribaschek A, Eichelmann K, Rudolph S, Fahlke J, Ridwelski K: Outpatient therapy with gemcitabine and docetaxel for gallbladder, biliary, and cholangio-carcinomas. Invest New Drugs 2002;20:351-356.
22 Taieb J, Mitry E, Boige V, Artru P, Ezenfis J, Lecomte T, Clavero-Fabri MC, Vaillant JN, Rougier P, Ducreux M: Optimization of 5-fluorouracil (5-FU)/cisplatin combination chemotherapy with a new schedule of leucovorin, 5-FU and cisplatin (LV5FU2-P regimen) in patients with biliary tract carcinoma. Ann Oncol 2002; 13:1192-1196.

23 Nehls O, Oettle H, Hartmann JT, Hofheinz RD, Hass HG, Horger MS, Koppenhofer U, Hochhaus A, Stieler J, Trojan J, Gregor M, Klump B: Capecitabine plus oxaliplatin as first-line treatment in patients with advanced biliary system adenocarcinoma: a prospective multicentre phase II trial. $\mathrm{Br}$ J Cancer 2008;98:309-315.

24 Reyes-Vidal JG, Yanez E, Rosas J, Palma M, Cerda B, Loredo E, Del Castillo C, Arriagada R, Quijada I: Gemcitabine $(G)$ and cisplatin (C) in the treatment of patients (pts) with unresectable or metastatic gallbladder cancer: results of the phase II GOCCHI study 2000 13. ASCO Annual Meeting, 2003.

25 Patt YZ, Hassan MM, Aguayo A, Nooka AK, Lozano RD, Curley SA, Vauthey JN, Ellis LM, Schnirer, II, Wolff RA, Charnsangavej C, Brown TD: Oral capecitabine for the treatment of hepatocellular carcinoma, cholangiocarcinoma, and gallbladder carcinoma. Cancer 2004;101:578-586.

26 Eng C, Ramanathan RK, Wong MK, Remick SC, Dai L, Wade-Oliver KT, Mani S, Kindler HL: A Phase II trial of fixed dose rate gemcitabine in patients with advanced biliary tree carcinoma. Am J Clin Oncol 2004;27:565-569.

27 Kornek GV, Schuell B, Laengle F, Gruenberger T, Penz M, Karall K, Depisch D, Lang F, Scheithauer W: Mitomycin C in combination with capecitabine or biweekly high-dose gemcitabine in patients with advanced biliary tract cancer: a randomised phase II trial. Ann Oncol 2004;15:478-483.

28 Knox JJ, Hedley D, Oza A, Feld R, Siu LL, Chen E, Nematollahi M, Pond GR, Zhang J, Moore MJ: Combining gemcitabine and capecitabine in patients with advanced biliary cancer: a phase II trial. J Clin Oncol 2005;23:2332-2338.

-29 Rao S, Cunningham D, Hawkins RE, Hill ME, Smith D, Daniel F, Ross PJ, Oates J, Norman AR: Phase III study of 5FU, etoposide and leucovorin (FELV) compared to epirubicin, cisplatin and 5FU (ECF) in previously untreated patients with advanced biliary cancer. Br J Cancer 2005;92:16501654.

30 Ducreux M, Van Cutsem E, Van Laethem JL, Gress TM, Jeziorski K, Rougier P, Wagener T, Anak O, Baron B, Nordlinger B: A randomised phase II trial of weekly highdose 5-fluorouracil with and without folinic acid and cisplatin in patients with advanced biliary tract carcinoma: results of the 40955 EORTC trial. Eur J Cancer 2005;41:398-403.
31 Julka PK, Puri T, Rath GK: A phase II study of gemcitabine and carboplatin combination chemotherapy in gallbladder carcinoma. Hepatobiliary Pancreat Dis Int 2006;5:110114.

32 Lee JO, Kim DY, Lim JH, Seo MD, Yi HG, Oh DY, Im SA, Kim TY, Bang YJ: Palliative chemotherapy for patients with recurrent hepatocellular carcinoma after liver transplantation. J Gastroenterol Hepatol 2009;24:800805.

33 Philip PA, Mahoney MR, Allmer C, Thomas J, Pitot HC, Kim G, Donehower RC, Fitch T, Picus J, Erlichman C: Phase II study of erlotinib in patients with advanced biliary cancer. J Clin Oncol 2006;24:3069-3074.

34 Manzione L, Romano R, Germano D: Chemotherapy with gemcitabine and oxaliplatin in patients with advanced biliary tract cancer: a single-institution experience. Oncology 2007;73:311-315.

$>35$ Hong YS, Lee J, Lee SC, Hwang IG, Choi SH, Heo JS, Park JO, Park YS, Lim HY, Kang WK: Phase II study of capecitabine and cisplatin in previously untreated advanced biliary tract cancer. Cancer Chemother Pharmacol 2007;60:321-328.

36 Riechelmann RP, Townsley CA, Chin SN, Pond GR, Knox JJ: Expanded phase II trial of gemcitabine and capecitabine for advanced biliary cancer. Cancer 2007;110:1307-1312.

37 Andre T, Reyes-Vidal JM, Fartoux L, Ross P, Leslie M, Rosmorduc O, Clemens MR, Louvet C, Perez N, Mehmud F, Scheithauer W: Gemcitabine and oxaliplatin in advanced biliary tract carcinoma: a phase II study. Br J Cancer 2008;99:862-867.

38 Im S, Kim Y, Kim H, Oh S, Choi I, Oh D, Kim J, Kim T, Kim S, Yoon Y, Bang Y: The role of thymidylate synthase as a pharmacogenomic predictor in a phase II trial of S-1/cisplatin in patients with metastatic or relapsed biliary tract cancer (BTC). Gastrointestinal Cancers Symposium, 2008.

39 Furuse J, Okusaka T, Boku N, Ohkawa S, Sawaki A, Masumoto T, Funakoshi A: S-1 monotherapy as first-line treatment in patients with advanced biliary tract cancer: a multicenter phase II study. Cancer Chemother Pharmacol 2008;62:849-855.

40 Meyerhardt JA, Zhu AX, Stuart K, Ryan DP, Blaszkowsky L, Lehman N, Earle CC, Kulke MH, Bhargava P, Fuchs CS: Phase-II study of gemcitabine and cisplatin in patients with metastatic biliary and gallbladder cancer. Dig Dis Sci 2008;53:564-570.

41 Valle JW, Wasan H, Johnson P, Jones E, Dixon L, Swindell R, Baka S, Maraveyas A, Corrie P, Falk S, Gollins S, Lofts F, Evans L, Meyer T, Anthoney A, Iveson T, Highley M, Osborne R, Bridgewater J: Gemcitabine alone or in combination with cisplatin in patients with advanced or metastatic cholangiocarcinomas or other biliary tract tumours: a multicentre randomised phase II study - The UK ABC-01 Study. Br J Cancer 2009;101:621-627. 
-42 Wagner AD, Buechner-Steudel P, Moehler M, Schmalenberg H, Behrens R, Fahlke J, Wein A, Behl S, Kuss O, Kleber G, Fleig WE: Gemcitabine, oxaliplatin and 5-FU in advanced bile duct and gallbladder carcinoma: two parallel, multicentre phase-II trials. Br J Cancer 2009;101:1846-1852.

43 Sasaki T, Isayama $\mathrm{H}$, Nakai $\mathrm{Y}$, Ito $\mathrm{Y}$, Togawa O, Yagioka H, Kogure H, Yasuda I, Hasebe O, Maetani I: Multicenter phase II study of gemcitabine (GEM) plus S-1 in patients (pts) with advanced biliary tract cancer (BTC). ASCO Annual Meeting, 2009.
44 Kim HJ, Lee NS, Lee SC, Bae SB, Kim CK, Cheon YG, Kim YS, Moon JH, Cho YD, Park SH, Lee KT, Park SK, Won JH, Park HS, Hong DS: A phase II study of gemcitabine in combination with oxaliplatin as first-line chemotherapy in patients with inoperable biliary tract cancer. Cancer Chemother Pharmacol 2009;64:371-377.

45 Ramanathan RK, Belani CP, Singh DA, Tanaka M, Lenz HJ, Yen Y, Kindler HL, Iqbal S, Longmate J, Mack PC, Lurje G, GandourEdwards R, Dancey J, Gandara DR: A phase II study of lapatinib in patients with advanced biliary tree and hepatocellular cancer. Cancer Chemother Pharmacol 2009;64: 777-783.

-46 Yamashita Y, Taketomi A, Itoh S, Harimoto N, Tsujita E, Sugimachi K, Gion T, Maehara Y: Phase II trial of gemcitabine combined with 5-fluorouracil and cisplatin (GFP) chemotherapy in patients with advanced biliary tree cancers. Jpn J Clin Oncol 2010;40:24-28.
47 Sharma A, Mohanti B, Raina V, Shukla N, Pal S, Dwary A, Deo S, Sahni P, Garg P, Thulkar S, DattaGupta S, Rath G: A phase II study of gemcitabine and oxaliplatin (Oxigem) in unresectable gall bladder cancer. Cancer Chemother Pharmacol 2010;65:497-502.

48 Jang JS, Lim HY, Hwang IG, Song HS, Yoo N, Yoon S, Kim YH, Park E, Byun JH, Lee MA, Oh SJ, Lee KH, Kim BS, Oh SC, Kim SY, Lee SJ: Gemcitabine and oxaliplatin in patients with unresectable biliary cancer including gall bladder cancer: a Korean Cancer Study Group phase II trial. Cancer Chemother Pharmacol 2010;65:641-647. 